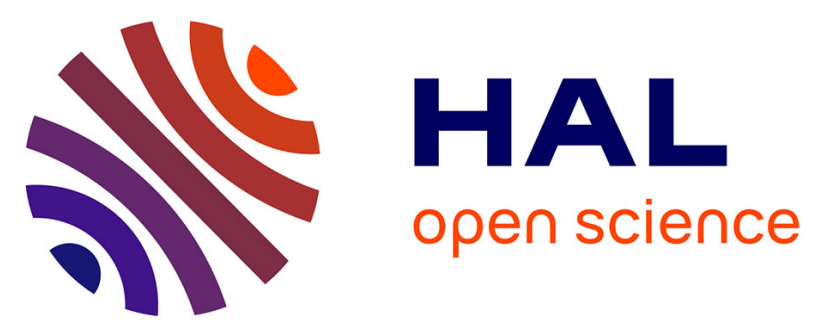

\title{
Test of an Original superconducting synchronous machine based on magnetic shielding
}

Rada Alhasan, Thierry Lubin, Bruno Douine, Zheksenbek Makeyevich Adilov, Jean Lévêque

\section{- To cite this version:}

Rada Alhasan, Thierry Lubin, Bruno Douine, Zheksenbek Makeyevich Adilov, Jean Lévêque. Test of an Original superconducting synchronous machine based on magnetic shielding. IEEE Transactions on Applied Superconductivity, 2016, 99, 10.1109/TASC.2016.2536785 . hal-01281359

\section{HAL Id: hal-01281359 \\ https://hal.science/hal-01281359}

Submitted on 2 Mar 2016

HAL is a multi-disciplinary open access archive for the deposit and dissemination of scientific research documents, whether they are published or not. The documents may come from teaching and research institutions in France or abroad, or from public or private research centers.
L'archive ouverte pluridisciplinaire HAL, est destinée au dépôt et à la diffusion de documents scientifiques de niveau recherche, publiés ou non, émanant des établissements d'enseignement et de recherche français ou étrangers, des laboratoires publics ou privés. 


\title{
Test of an Original Superconducting Synchronous Machine Based on Magnetic Shielding
}

\author{
Rada Alhasan, Thierry Lubin, Bruno Douine, Zheksenbek Makeyevich Adilov, Jean Lévêque
}

\begin{abstract}
In this paper, we present a new kind of superconducting inductor for a synchronous machine. This inductor is composed of two superconducting coils (solenoids) having the same axis and fed by the same current. A superconducting bulk is used to obtain a variation of the flux density in the air-gap. This superconducting bulk is surrounded by a ferromagnetic material in order to improve the distribution of the radial component of the flux density. With the studied inductor, we obtain a two-pole synchronous machine having a high magnetic field value in the air-gap. The main objective of this paper is to show the feasibility of this new concept of inductor.
\end{abstract}

Index Terms - Electrical engineering, Superconducting motors, Superconducting coils, Electromagnetic shield.

\section{INTRODUCTION}

$I^{2}$ MPROVING the performance of electrical machines is always a big challenge for all manufacturers and academic researchers. By increasing the magnetic field in the electrical machine, it is possible to improve the machine's performances. The characteristics of the superconducting materials are very interesting and promising to design high performances generators or motors. One of the main important properties of superconducting materials is their abilities of suppressing the Joule losses and their very high current densities. Therefore, these materials are convenient to generate high magnetic field in the air-gap in order to obtain high performance electrical machines. Another of the advantages is the ability of a bulk superconducting material to screen or to trap the magnetic field.

A lot of superconducting inductors using superconducting wires or bulks have been designed and tested. So, many experimental and modeling studies have shown the ability of the superconductor materials to be used as a field inductor for synchronous motors [1-5].

It is well known that when a superconducting bulk is cooled down under zero magnetic field, it becomes a magnetic screen. Indeed, when an external magnetic field is applied, superficial currents are developed, according to Lenz's law. This behavior can be used to guide or to screen the magnetic flux, because the magnetic flux stays equal to zero in the superconducting material as show in Fig. 1.

Rada Alhasan, Thierry Lubin, Bruno Douine, and Jean Leveque are with the Groupe de Recherche en Electrotechnique et Electronique de Nancy, Université de Lorraine (GREEN), Nancy-FRANCE.

Zheksenbek Makeyevich Adilov is with Kazakh National Technical University, KazNTU, Named after K.I. Satybayev, 22 Satybayev, 050013 Almaty, KAZAKSTHAN.
In this paper, we study an original topology of superconducting inductor for synchronous motor. The main goal of this paper is to prove the feasibility of this new concept. No design optimization and no comparison with more conventional electrical machines are made at the present time. This will be done in future works. Compared to more conventional superconducting synchronous machines [7]-[12], the proposed inductor presents an original structure. As shown in Fig. 2, it is composed of two superconducting field coils and a superconducting bulk which is used as a magnetic screen. The coils are really easy to manufacture because they have a solenoid form. This new inductor leads to a significant increase for the air-gap flux density.

In this paper, We study the performances of this inductor thanks to numerical analysis using a 3-D finite element software and measurements.

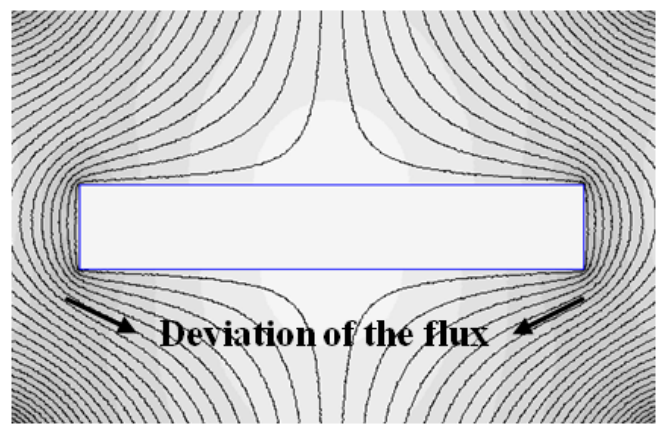

Fig.1. Shielding effect obtained with a superconducting bulk.

\section{STRUCTURE OF THE SUPERCONDUCTING INDUCTOR}

The studied electrical motor is composed of a classical stator yoke and an original superconducting inductor. The study developed in this part concerns the superconducting inductor and the effect of the stator yoke on the air-gap flux density distribution.

\section{A. Description of the inductor}

The structure of this new kind of inductor is described in Fig. 2. This inductor includes two superconducting coils and a superconducting screen which is placed between them.

The two coils are fed by the same electrical current. They create a magnetic field oriented in the same direction as shown in Fig.2.

A superconducting plate is inserted between the two coils. The superconducting plate is positioned such that it acts as a magnetic screen. This bulk leads to a spatial variation of the magnetic-field in the air-gap. 


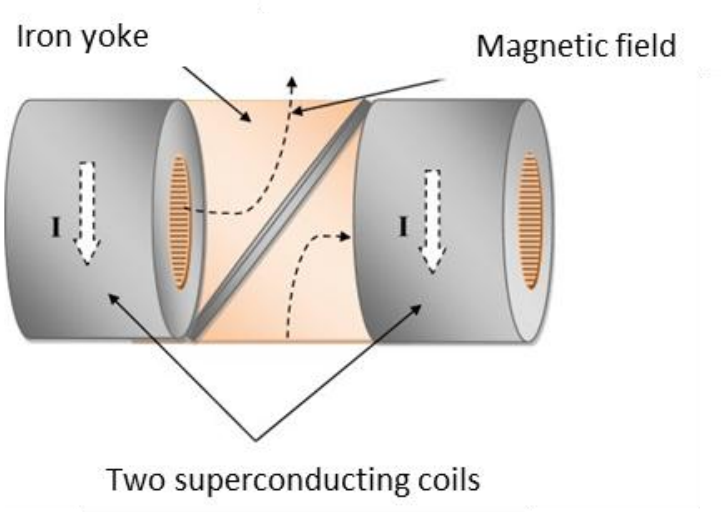

Fig.2. Structure of the studied inductor.

We use a ferromagnetic material between and inside the two coils in order to increase the radial component of the flux density in the air-gap.

By this way, we design a two-pole machine. This topology could be compared to a claw pole synchronous machine [6]. We have designed this superconducting inductor in order to obtain a high magnetic flux in the air-gap, and therefore an important value for the electromagnetic torque.

In Fig. 3, we show the path of the magnetic flux lines for the studied superconducting motor. These flux lines are different from that usually encountered in conventional machines.

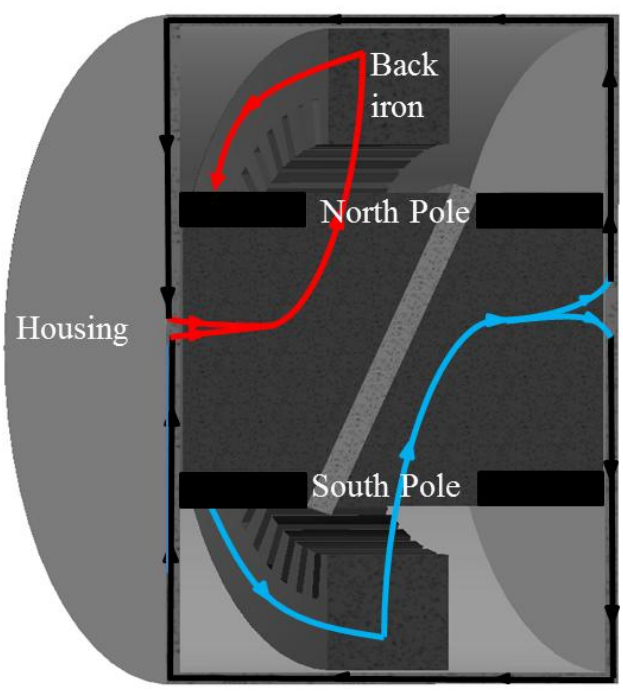

Fig. 3. Flux lines distribution with the back iron.

\section{B. Study of the inductor}

The geometrical parameters and some specification of the studied inductor are given in table I and table II and are shown in Fig. 4.

TABLE I

GEOMETRICAL PARAMETERS

\begin{tabular}{lll}
\hline \hline \multicolumn{1}{c}{ Name } & \multicolumn{1}{c}{ Quantity } & Value \\
\hline$R_{\text {ext }}(\mathrm{mm})$ & External radius & 68 \\
$C(\mathrm{~mm})$ & Distance between the solenoids & 45 \\
$L(\mathrm{~mm})$ & Length of the solenoids & 45 \\
$E(\mathrm{~mm})$ & Thickness of superconducting plate & 10 \\
$J\left(\mathrm{~A} / \mathrm{mm}^{2}\right)$ & Current density & 700 \\
\hline
\end{tabular}

TABLE II

SPECIFICATION OF THE SUPERCONDUCTORS

\begin{tabular}{ll}
\hline \hline \multicolumn{1}{c}{ Name } & \multicolumn{1}{c}{ Characteristics } \\
\hline Coils & $\mathrm{NbTi}$ \\
Superconducting plate & YBCO \\
Operating temperature $(K)$ & 4.2 \\
\hline
\end{tabular}

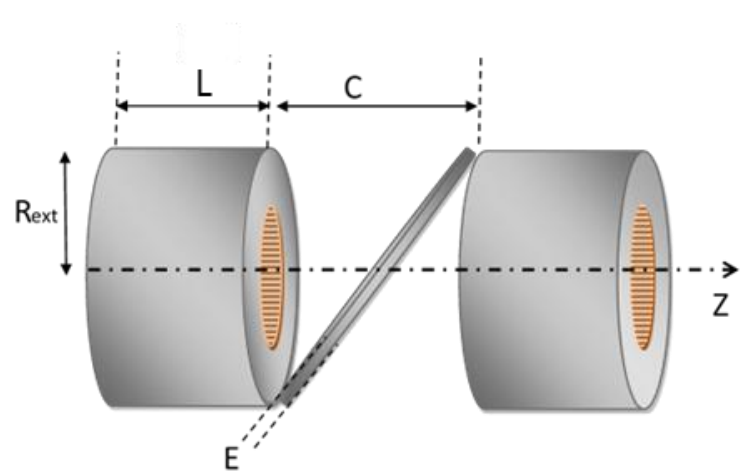

Fig.4. The inductor dimensions.

The active part of the motor is between the two coils. Therefore, the active part corresponds to one third of the total length. If we compare with a two pole classical motor, this value is almost the same due to the winding overhangs that can be found in classical two pole machine.

The distribution of the radial component of the flux density $B_{r}$ along the $\mathrm{z}$-axis (between the two coils and for an angle of $\pi / 2$ ) is computed at a distance of two centimeters from the inductor. This radius corresponds to the large value of the airgap due to the cryostat. We present in Fig. 5 the lines where the magnetic field is computed.

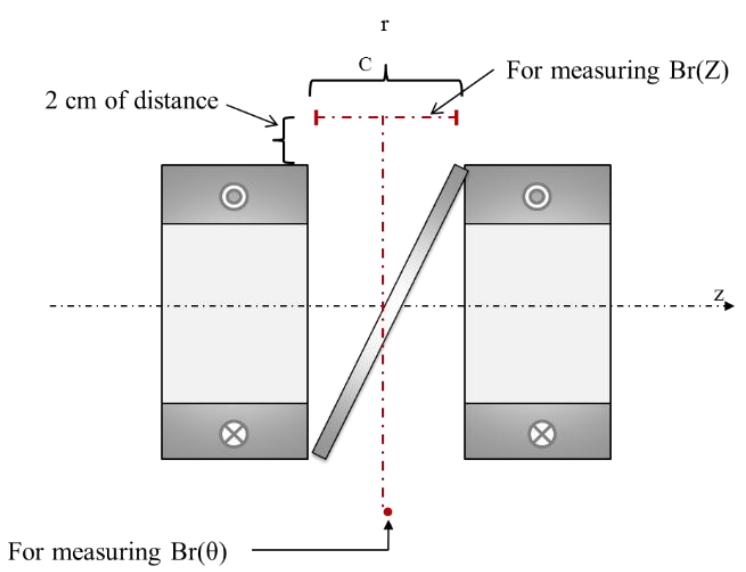

Fig.5. Lines where the radial component of the flux density is computed.

We can observe in Fig. 6 that the magnetic field decreases and becomes negative at the end of the active part of the rotor. We can note that the magnetic flux is not constant along the $\mathrm{z}$ axis, unlike as is often the case in a conventional motor. This can be observed more clearly in Fig. 7 where the radial component of the flux density is described in the air-gap region in the plane $(\theta, z)$. 


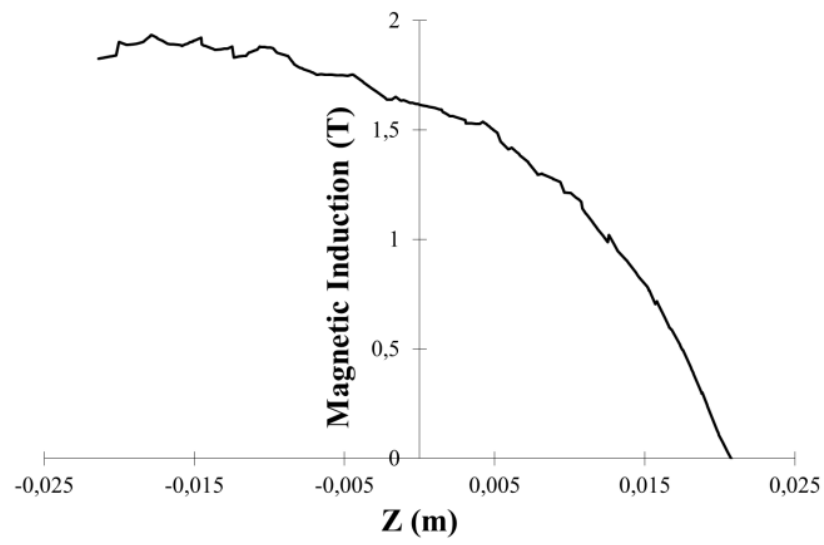

Fig.6. Radial component of the flux density in the airgap along the z-axis.

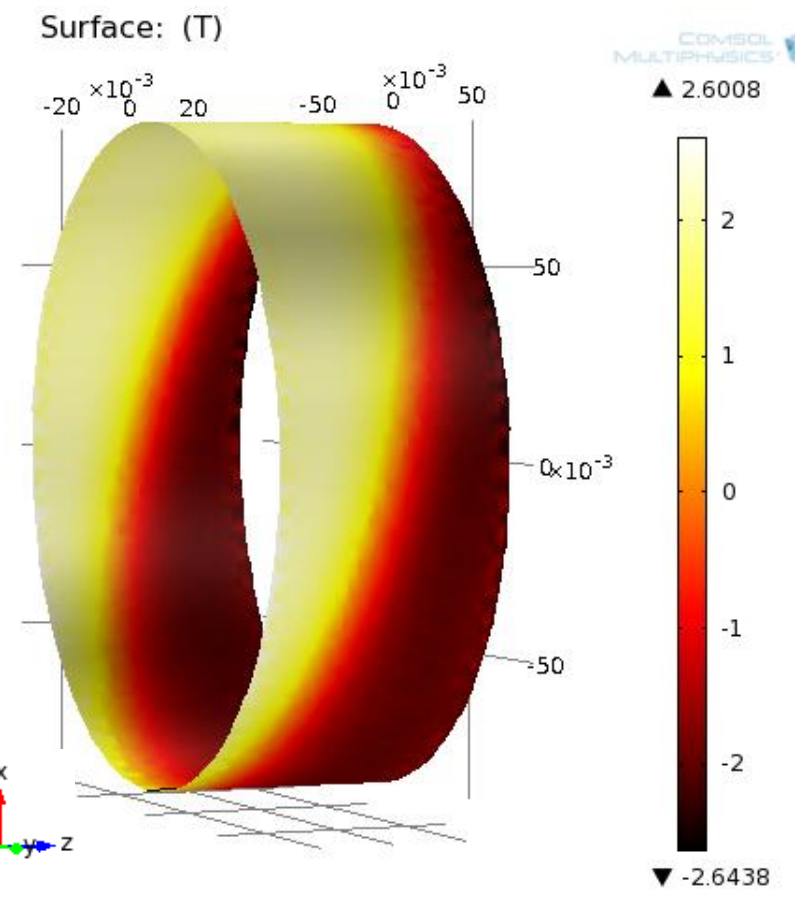

Fig.7. Mapping of the radial component of the flux density in the plane $(\theta, z)$

From the magnetic flux density distribution in the air-gap given in Fig. 7, we can compute the electromotive force induced in the armature. Due to the important airgap value, the magnetic flux and the back-EMF have a sinusoidal shape as it can be observed in Fig. 8 .

A very important point for the design of this kind of superconducting motor concerns the air-gap length value. With the proposed inductor, we can obtain a very high value of the flux density which can reach a value up to 6 Tesla for a small air-gap value as shown in Fig. 9. This value decreases with the increase of the magnetic air-gap between the inductor and the armature as it can be observe in Fig. 9. Therefore, for this kind of motor, more than for all others, it is important to reduce the air-gap length. With a ten millimeter air-gap, which is possible with an optimization of the design of the cooling system (cryostat), we can obtain a technological breakthrough

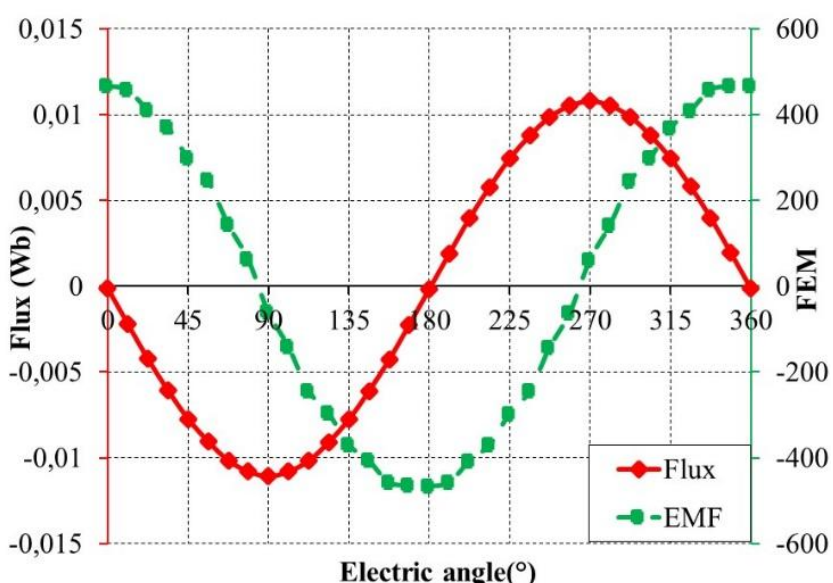

Fig.8. Magnetic flux and back EMF computed with 3D FE simulations.

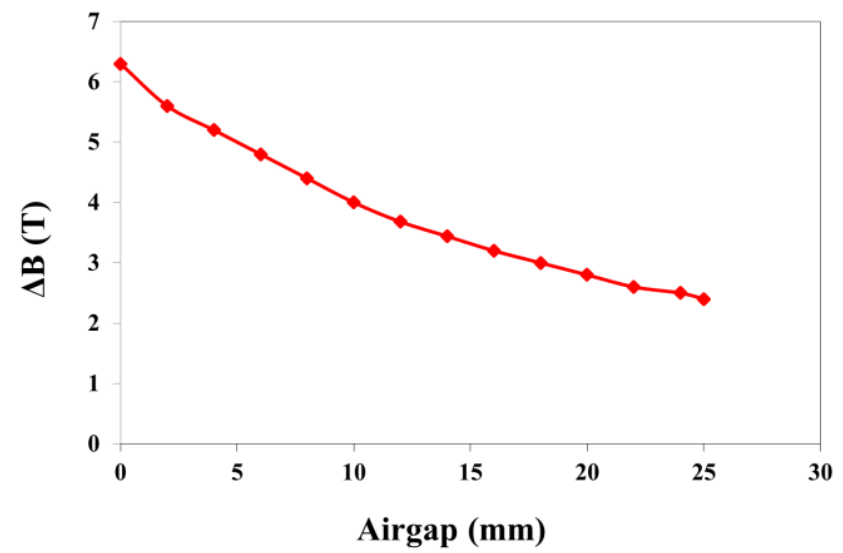

Fig.9. Variation of the flux density with the air-gap length.

\section{EXPERIMENTAL RESULTS}

We have conducted two types of tests. The first one concerns the inductor taken alone. The second concerns the whole system including the inductor and the armature.

\section{A. Test of the inductor alone}

For this test, the inductor is immersed in liquid nitrogen. In this case, the YBCO plate is in a superconducting state. The superconducting coils, which are made with $\mathrm{NbTi}$ wires, are in normal state. We therefore supplied these superconducting coils at a low current value in order to avoid an overheating and their destruction. We used a Hall probe to measure the magnetic field around the inductor. We can notice from Fig. 10 and Fig. 11 good agreements between calculations and measurements. The small differences can be explained by a positioning error for the Hall probe around the inductor. These curves show the ability to obtain a spatial variation of the magnetic field with our inductor. 


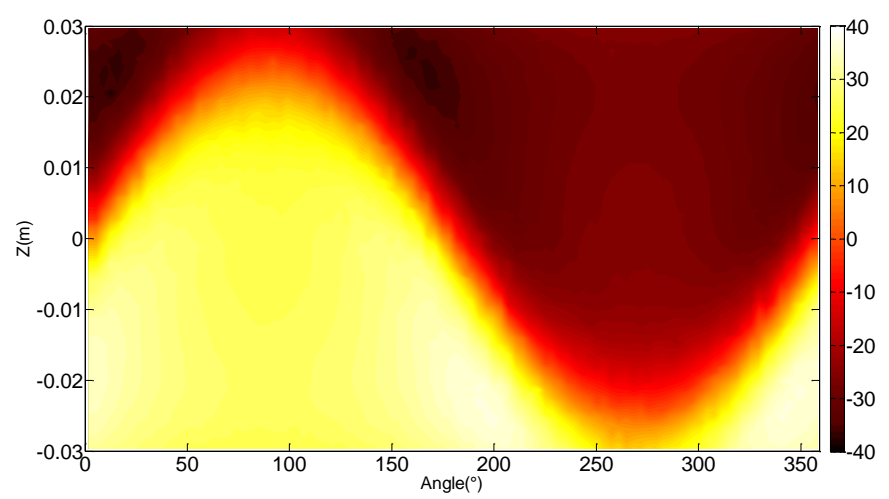

Fig.10. Magnetic field in air-gap (3D FE simulation).

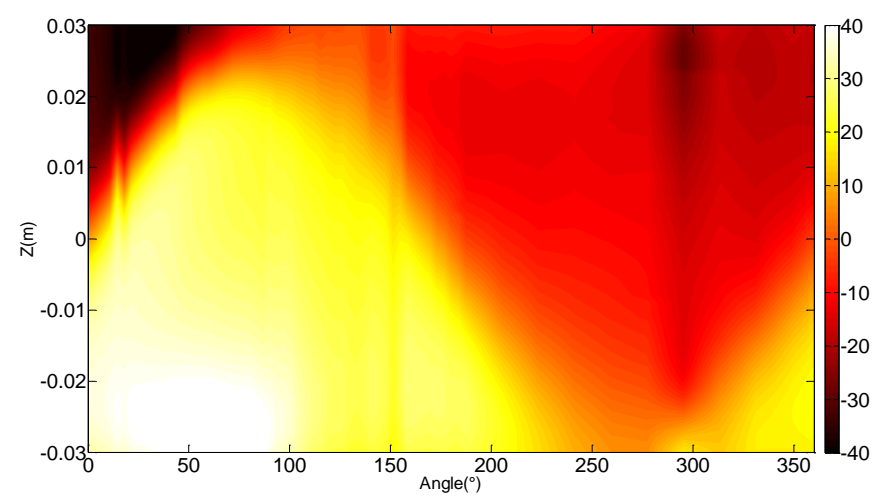

Fig.11. Magnetic field in the airgap (measurement with a Hall probe).

\section{B. Test of the whole system}

The last step in the study of our system is to show that it is possible to make a motor with this shape of magnetic flux in the air-gap. To prove it, we have built a superconducting machine which is presented in Fig. 12.

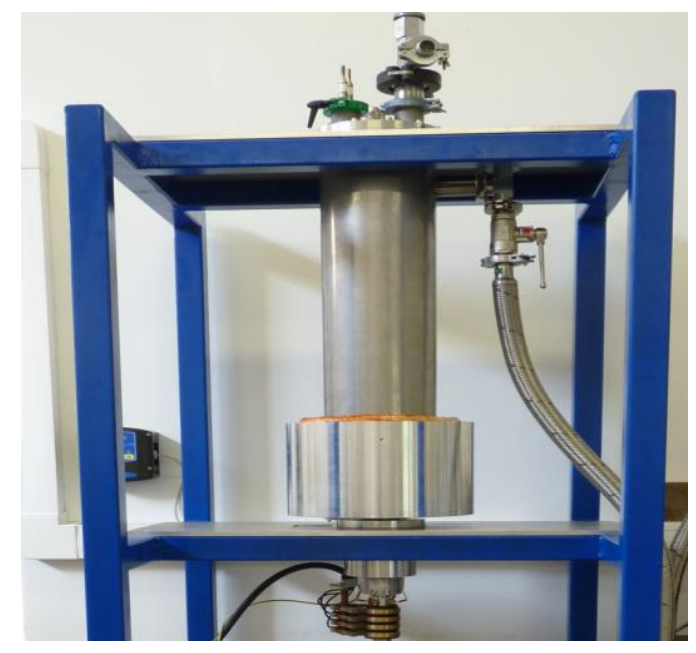

Fig.12. Photography of the superconducting motor.
The main characteristics of this superconducting motor are summarized in table III.

TABLE III

PARAMETERS OF THE SUPERCONDUCTING MOTOR

\begin{tabular}{llll}
\hline \hline \multicolumn{1}{c}{ Parameters } & Unit & Value \\
\hline Pole pairs & & 2 \\
Nominal speed & $\mathrm{rpm}$ & 500 \\
Motor air gap & $\mathrm{mm}$ & 18 \\
$\begin{array}{l}\text { Number of slots of the armature } \\
\text { (three phase windings) }\end{array}$ & & 48 \\
\hline
\end{tabular}

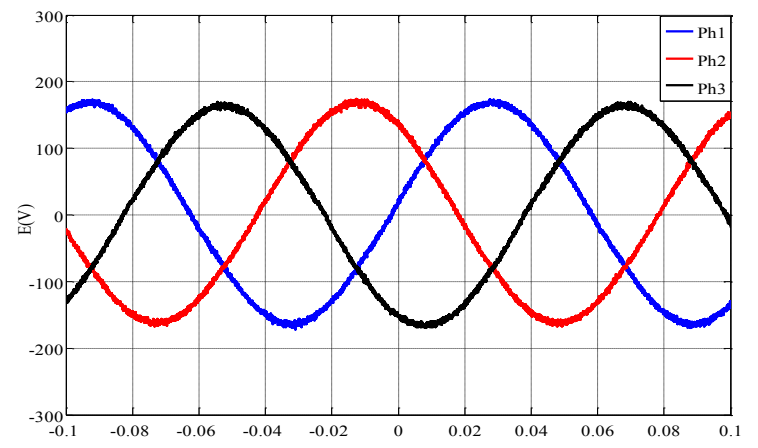

Fig.13. Experimental back EMF for the superconducting motor

The back-EMF measurement of the studied machine is given in Fig .13. We obtain a three phase voltage system with our system. The voltage waveform is sinusoidal. This is due to the important value for the air gap that represents a natural filter for the harmonics of the magnetic field.

By this way we have proven the feasibility of a new concept of superconducting inductor and motor.

\section{CONCLUSION}

In this paper, we have designed and built a new superconducting inductor. This new superconducting inductor has been used to build a superconducting motor. We have conducted tests for the inductor alone and for the superconducting motor. The results presented in this paper show the ability to design a flux barrier superconducting inductor. In future works, this structure will be optimized and compared in terms of performance with more conventional superconducting motors.

\section{REFERENCES}

[1] T. Kiyoshi, S. Choi, S. Matsumoto, T. Asano, et D. Uglietti, "Magnetic flux concentrator using $\mathrm{Gd}-\mathrm{Ba}-\mathrm{Cu}-\mathrm{O}$ bulk superconductors". IEEE Trans. Appl. Supercond, Vol. 19, No. 3 (June 2009), pp. 2174-2177.

[2] E. Ailam, D.Netter, J.Lévêque, B.Douine, Philippe J. Masson, Member, IEEE, and A.Rezzoug, Member, IEEE, "Design and testing of a superconducting rotating machine", IEEE Trans. Appl. Supercon., Vol. 17, No. 1, March 2007.

[3] R.Moulin, J.Lévêque, L.Durantay, B.Douine, D.Netter, and A.Rezzoug, Member, IEEE, "Superconducting multistack inductor for synchronous motors using the diamagnetism property of bulk material", IEEE transactions on industrial electronics, Vol. 57, No. 1, January 2010.

[4] D. Netter, J. Leveque, E. Ailam, B. Douine, A. Rezzoug, and Philippe J. Masson, "Theoretical study of a new kind HTS motor", IEEE Trans. Appl. Supercon., Vol. 15, No. 2, (June 2005) 
[5] P. Masson, J. Leveque, D. Netter, and A. Rezzoug, "Experimental study of a new kind of superconducting inductor". IEEE Trans. Appl. Superconductor., Vol. 13, No. 2, Jun. 2003, pp. 2239-2242.

[6] G. Barakat, A. Foggia, M. Ivanes, R. Periot, A. Masson, "Three dimensional computation of claw-pole synchronous machine performances". in Proc. Int. Conf. Elect. Mach. (ICEM), Vol.3 (1994), pp.116-121.

[7] S. Fukui et al., "Numerical study of optimization design of high temperature superconducting field winding in $20 \mathrm{MW}$ synchronous motor for ship propulsion," IEEE Trans. Appl. Supercond., vol. 22, no. 3, Jun. 2012, Art. ID. 5200504.

[8] R. Shafaie and M. Kalantar, "Design of a 10-MW-class wind turbine HTS synchronous generator with optimized field winding," IEEE Trans. Appl. Supercond., vol. 23, no. 4, Aug. 2013, Art. ID. 5202307.

[9] V. Dombrovski, D. Driscoll, B. A. Shoykhet, S. D. Umans, and J. K. Zevchek, "Design and testing of a 1000-hp high-temperature superconducting motor," IEEE Trans. Energy Convers., vol. 20, no. 3, pp. 638-643, Sep. 2005.

[10] M. Yazdanian, P. Elhaminia, M. R. Zolghadri, and M. Fardmanesh, "Analytical modeling of magnetic flux in superconducting synchronous machine," IEEE Trans. Appl. Supercond., vol. 23, no. 1, Feb. 2013, Art. ID. 5200406.

[11] J. J. Lee, Y. S. Jo, J. P. Hong, and Y. K. Kwon, "Design of field coil for 100-hp-class HTS motor considering operating current," IEEE Trans. Appl. Supercond., vol. 13, no. 2, pp. 2214-2216, Jun. 2003.

[12] A. B. Abrahamsen, N. Mijatovic, E. Seiler, and M. P. Sorensen, "Design study of $10 \mathrm{~kW}$ superconducting generator for wind turbine applications," IEEE Trans. Appl. Supercond., vol. 19, no. 3, pp. 16781682, Jun. 2009. 